\title{
Определение концентрации свободных носителей заряда в легированных бором кремниевых нанонитях при помощи инфракрасной спектроскопии в режиме нарушенного полного внутреннего отражения
}

\author{
(C) Е.А. Липкова ${ }^{1}$, А.И. Ефимова ${ }^{1, \uparrow}$, К.А. Гончар ${ }^{1}$, Д.Е. Преснов ${ }^{2,1}$, А.А. Елисеев ${ }^{3}$, \\ А.Н. Лапшин ${ }^{4}$, В.Ю. Тимошенко ${ }^{1,5,6}$ \\ ${ }^{1}$ Московский государственный университет им. М.В. Ломоносова (физический фракультет), \\ 119991 Москва, Россия \\ ${ }^{2}$ Московский государственный университет им. М.В. Ломоносова (НИИЯФ им. Д.В. Скобельцина), \\ 119234 Москва, Россия \\ ${ }^{3}$ Московский государственный университет им. М.В. Ломоносова (факультет наук о материалах), \\ 119991 Москва, Россия \\ ${ }^{4}$ ООО „Брукер“, \\ 119017 Москва, Россия \\ ${ }^{5}$ Национальный исследовательский ядерный университет „МИФИ“, \\ 115409 Москва, Россия \\ ${ }^{6}$ Физический институт им. П.Н. Лебедева Российской академии наук, \\ 119991 Москва, Россия \\ ฯ E-mail: efimova@vega.phys.msu.ru
}

Поступила в Редакцию 13 мая 2019 г.

В окончательной редакции 24 мая 2019 г.

Принята к публикации 24 мая 2019 г.

\begin{abstract}
Методом инфракрасной спектроскопии в режиме нарушенного полного внутреннего отражения определена концентрация свободных носителей заряда в массивах кремниевых нанонитей с характерными поперечными размерами 50-100 нм и длиной 10 мкм, сформированных на низколегированных подложках кристаллического кремния $p$-типа проводимости методом металл-стимулированного химического травления и подвергнутых дополнительному термодиффузионному легированию бором при температурах $850-1000^{\circ} \mathrm{C}$. Установлено, что в зависимости от температуры отжига концентрация свободных дырок в массивах варьируется от $5 \cdot 10^{18}$ до $3 \cdot 10^{19} \mathrm{~cm}^{-3}$ и максимальна при температурах $900-950^{\circ} \mathrm{C}$. Полученные результаты могут быть использованы для расширения области применения кремниевых нанонитей в фотонике, сенсорике и термоэлектрических преобразователях энергии.
\end{abstract}

Ключевые слова: легированные кремниевые нанонити, спектроскопия нарушенного полного отражения, свободные носители заряда, металлстимулированное химическое травление.

DOI: 10.21883/FTP.2019.11.48455.9157

\section{1. Введение}

Кристаллический кремний $(c-\mathrm{Si})$ является основным материалом современной микроэлектроники и солнечной энергетики. Переход от объемных форм кремния к кремниевым наноструктурам позволяет расширить область его практического применения в фотонике, сенсорике и термоэлектрике [1-3]. В частности, для фотоники представляют интерес анизотропные кремниевые наноструктуры, в которых могут быть реализованы исключительно сильные двулучепреломление и дихроизм, зависящие от концентрации свободных носителей заряда [4]. Одним из перспективных в практическом плане видов кремниевых наноструктур являются кремниевые нанонити (КНН), формируемые методом металлстимулированного химического травления (МСХT) [1,5]. Особенностью этого метода является зависимость характерных размеров и морфологии КНН от уровня легирования исходных подложек $c$-Si [6].
Одним из направлений получения КНН с контролируемыми структурными параметрами и заданным уровнем легирования является дополнительное легирование сформированных массивов КНН, например, путем термодиффузии [7,8], что позволяет управлять как концентрацией, так и типом носителей заряда. Так, в работе [7] установлено, что путем термодиффузии из газовой фазы хлорида бора в уже сформированные КНН могут быть получены легированные образцы, которые проявляют высокую эффективность термоэлектронного преобразования при низкой электропроводности ( 3 мОм · см). Однако из работы [7] неясно, какой вклад в величину электропроводности вносят концентрация и подвижность свободных носителей заряда. В то же время важной задачей является выявление зависимости концентрации носителей заряда от условий легирования, в частности от температуры диффузии. Возможность изменять уровень легирования в широком интервале 
Таблица 1. Исследуемые образцы и их параметры (толщина, эффективный показатель преломления и пористость массива КНH)

\begin{tabular}{c|c|c|c}
\hline $\begin{array}{c}\text { Массив } \\
\text { КНН }\end{array}$ & $\begin{array}{c}\text { Толщина } \\
\text { массива (длина } \\
\text { нанонитей) } \\
L, \text { мкм }\end{array}$ & $\begin{array}{c}\text { Эффективный } \\
\text { показатель } \\
\text { преломления } \\
\left\langle n_{\text {eff }}\right\rangle\end{array}$ & $\begin{array}{c}\text { Пористость } \\
(\text { по данным } \\
\text { СЭМ) } \\
p, \%\end{array}$ \\
\hline А & $7.5 \pm 0.5$ & $1.8 \pm 0.2$ & $68 \pm 7$ \\
В & $13.5 \pm 0.5$ & $2.1 \pm 0.2$ & $70 \pm 9$
\end{tabular}

позволит расширить спектр применения КНН в различных областях науки и техники.

В работе [8] постлегирование выполнялось методом быстрого термического отжига предварительно введенных в массив наноструктурированного кремния примесей, содержащих фосфор, что позволило достичь концентрации свободных электронов в $3.4 \cdot 10^{19} \mathrm{~cm}^{-3}$. При этом был использован бесконтактный метод диагностики при помощи инфракрасной (ИК) спектроскопии в режиме нарушенного полного отражения (НПВО). Необходимо отметить, что применение последнего метода требует привлечения модели эффективной среды для анализа экспериментальных результатов [9].

В данной работе изучено влияние температур отжига на концентрацию свободных носителей заряда (дырок) в КНН, сформированных методом МСХТ на низколегированных подложках $c$-Si. Анализ концентрации дырок выполнялся с использованием метода ИК-спектроскопии в режиме нарушенного полного внутреннего отражения.

\section{2. Методика эксперимента}

В работе исследовались массивы КНН, сформированные двухступенчатым методом МСXТ [1] на подложках слабо легированного бором кристаллического кремния $p$-Si(100) с удельным сопротивлением (10-15) Ом · см $\left(N_{p} \approx 10^{15} \mathrm{~cm}^{-3}\right)$. Путем варьирования времени травления были сформированы два набора образцов с толщиной массивов КНН (длиной нанонитей), равной $7.5 \pm 0.5$ мкм - образцы А и $13.5 \pm 0.5$ мкм - образцы В соответственно (см. табл. 1).

Легирование КНН примесью бора проводилось путем нанесения технологической смеси, содержащей раствор борной кислоты в этиловом спирте, которая применяется для диффузионного легирования планарных микроструктур, и дальнейшего отжига в муфельной печи в потоке аргона. Отжиг проводился в течение 10 мин при температурах $850,900,950$ и $1000^{\circ} \mathrm{C}$, обеспечивающих термодиффузию бора в объеме материала, и сопровождался охлаждением в потоке аргона вне зоны реактора для предотвращения дополнительного окисления поверхности КНН. Остатки легирующего состава и оксидное покрытие удалялись путем кратковременной $(2-3$ c) выдержки образцов в плавиковой кислоте (48\%) с последующей промывкой в деионизованной воде. Далее образцы высушивались на воздухе при комнатной температуре.

Морфология, характерные размеры образцов и пористость приповерхностной области определялись с помощью сканирующего электронного микроскопа (СЭМ) Carl Zeiss Supra 40. Оптические свойства КНН в инфракрасном диапазоне исследовались на фурьеспектрометрах Bruker IFS 66v/S и Bruker Alpha, последний был оснащен приставкой НПВО с германиевым кристаллом однократного отражения с углом скоса $45^{\circ}$.

\section{3. Результаты и обсуждение}

На рис. 1 приведены СЭМ-изображения поверхности и боковых сколов полученных образцов. Видно, что нанонити обоих типов образцов имеют поперечное сечение $\sim 100$ нм. Анализ СЭМ-изображений поверхности с помощью программы Photoshop позволяет оценить пористость приповерхностного слоя, которая составила $\sim 70 \%$ (см. табл. 1). Совпадение значений пористости в пределах погрешности указывает на неизменность морфологии массивов нанонитей при увеличении длительности их формирования в процессе МСXТ. Постлегирование массивов КНН также практически не изменяло морфологию нитей.

На рис. 2 представлены спектры зеркального отражения (далее - отражения) исходного и постлегированных, при различных температурах отжига, массивов КНН на примере образца А. Интерференционные особенности, наблюдающиеся в спектрах отражения как исходных, так и легированных образцов, свидетельствуют о применимости модели эффективной среды в дальнем и части среднего ИК-диапазонах спектра к описанию оптических свойств массивов КНН. С увеличением волнового числа контраст интерференционной картины в спектрах снижается за счет рассеяния на кремниевых нанонитях. Последнее превалирует на волновых числах в 1000-2000 см ${ }^{-1}$ и выше. Отметим, что интерференция и рассеяние значительно искажают область плазменного минимума, что не позволяет определить концентрацию СН3, используя стандартный подход, который был применен ранее при анализе слоев мезопористого кремния [10].

Наличие интерференционных особенностей в спектрах отражения позволяет определить среднее на интервале 500-2500 см-1 значение эффективного показателя преломления массивов КНН $\left\langle n_{\text {eff }}\right\rangle$ (табл. 1) и убедиться в применимости германиевого кристалла с углом скоса $45^{\circ}$ для регистрации спектров НПВО исследуемых массивов. Величины $\left\langle n_{\text {eff }}\right\rangle$ не изменялись в пределах ошибки при легировании образцов. Кроме того, по эффективному показателю преломления $\left\langle n_{\mathrm{eff}}\right\rangle$ в рамках модели эффективной среды (формула Бруггемана) [9] была оценена пористость массивов КНН, которая оказалась близка к значениям, извлеченным из анализа картин СЭМ. Полученные результаты показывают, что 
$a$
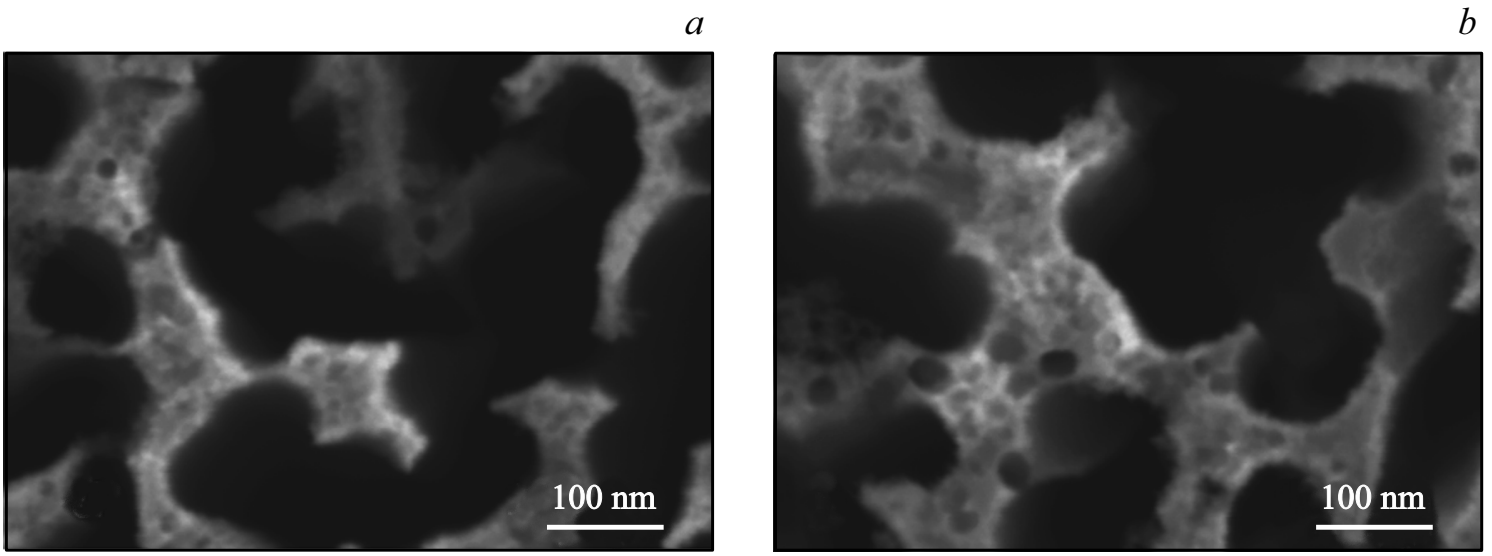

$c$
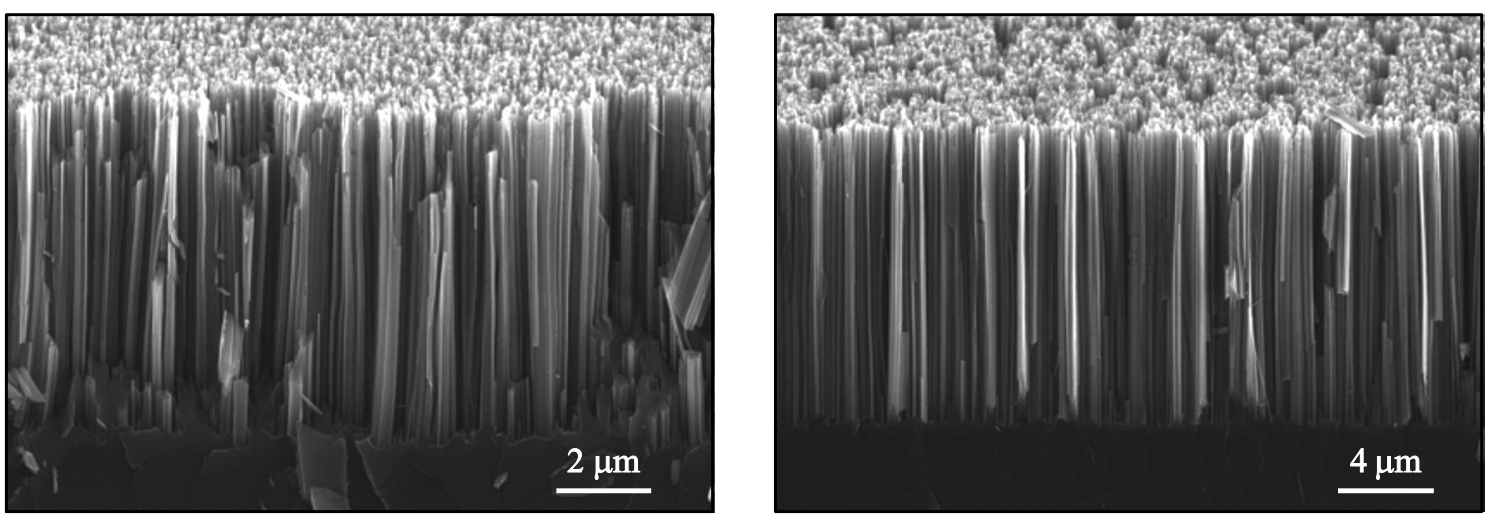

Рис. 1. СЭМ-изображения исходных образцов А $(a, c)$ и $\mathrm{B}(b, d)$.

при анализе массивов КНН можно оценивать пористость по СЭМ-изображениям поверхности. Показатель же преломления может быть оценен (без учета его дисперсии) из пористости массива по модели эффективной среды, при этом спектры зеркального отражения играют вспомогательную роль.

Для определения концентрации СН3 в массивах КНН нами был использован режим НПВО, для которого

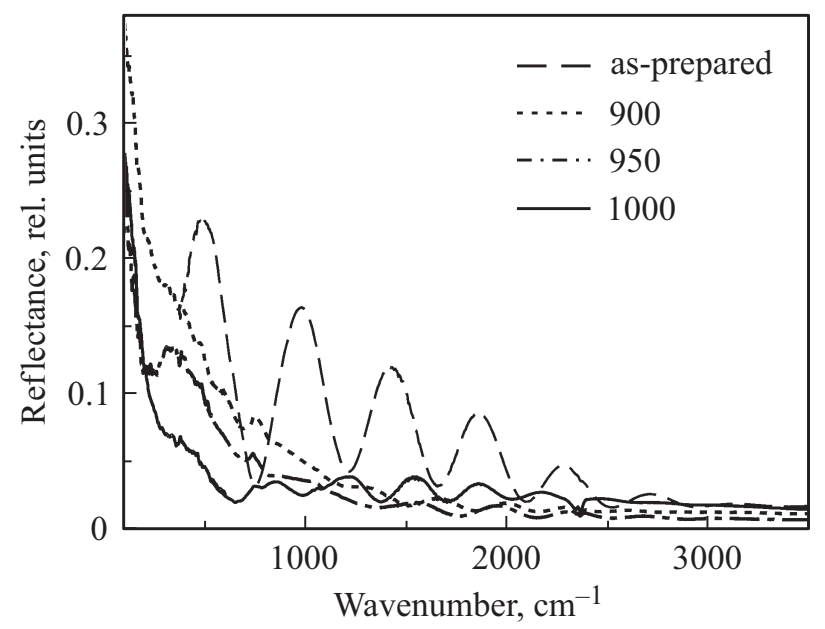

Рис. 2. Спектры зеркального отражения образца А до и после термодиффузии бора при температурах 900,950 и $1000^{\circ} \mathrm{C}$. не существенно влияние интерференции и рассеяния света [11]. На рис. 3 представлены спектры НПВО исходного и постлегированного при разных температурах отжига образца А. Отражение массива нелегированных КНН в режиме НПВО близко к единице, за исключением полос, относящихся к поглощению в оксиде кремния в диапазоне 1000-1200 и вблизи $460 \mathrm{~cm}^{-1}$. В спектрах легированных массивов наблюдается значительное уменьшение сигнала НПВО в области малых волновых чисел, которое обусловлено поглощением световой волны на свободных носителях заряда в КНН.

Для количественного анализа данных НПВО необходимо учесть, что при падении неполяризованного излучения спектр НПВО $R_{A T R}$ массива КНН можно выразить следующим образом [8]:

$$
R_{A T R}=\left(R_{s}+R_{s}^{2}\right) / 2
$$

где

$$
R_{s}=\left|\frac{n_{\mathrm{Ge}}-n_{\mathrm{eff}} \sqrt{2-\frac{n_{\mathrm{Ge}}^{2}}{n_{\mathrm{eff}}^{2}}}}{n_{\mathrm{Ge}}+n_{\mathrm{eff}} \sqrt{2-\frac{n_{\mathrm{Ge}}^{2}}{n_{\mathrm{eff}}^{2}}}}\right|^{2} .
$$

В выражении (2) $n_{\mathrm{Ge}}$ - показатель преломления германия, а эффективный показатель преломления массива 

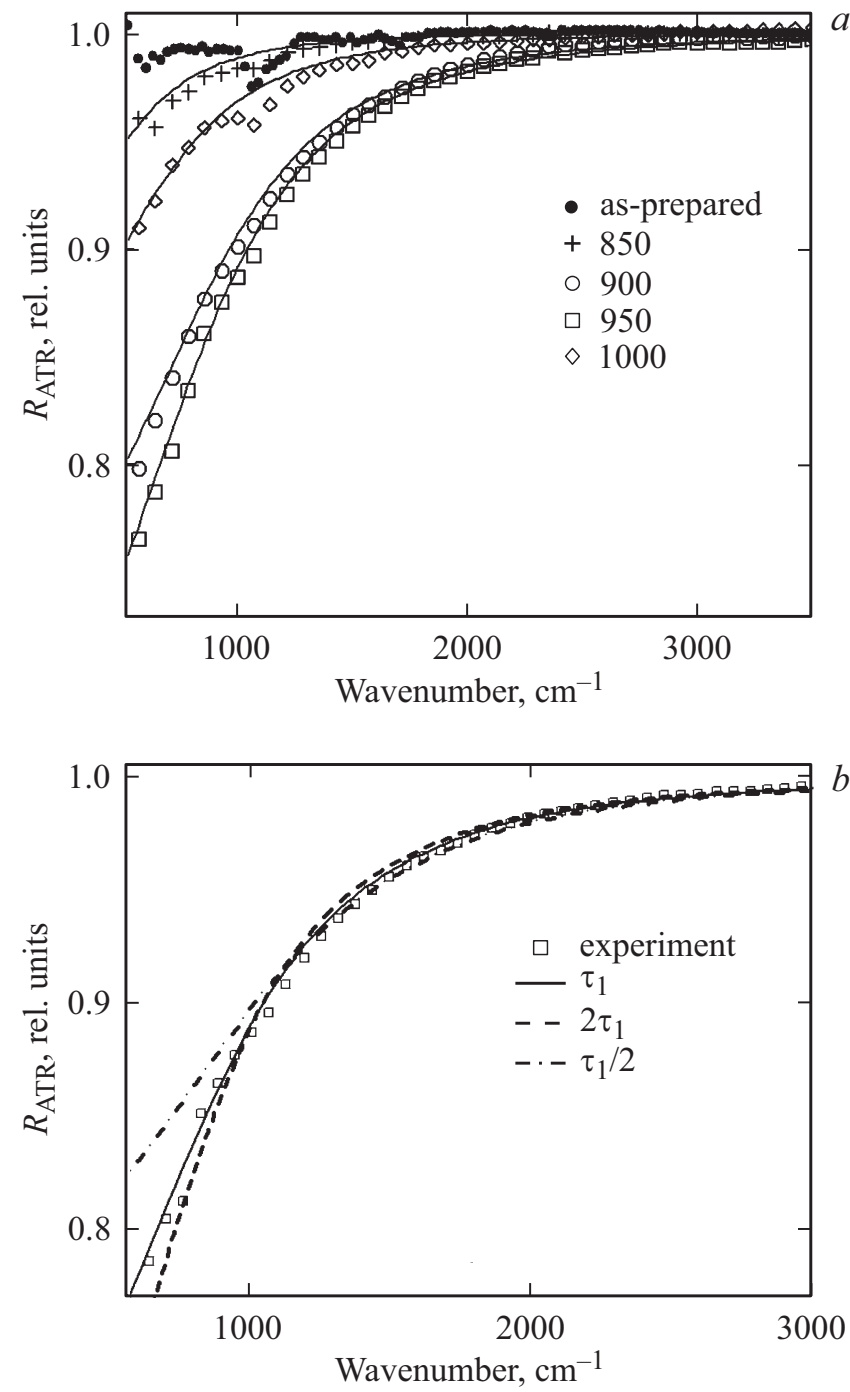

Рис. 3. Спектры НПВО образца А до и после термодиффузии бора при температурах $850,900,950$ и $1000^{\circ} \mathrm{C}$, сплошные линии - моделирование спектров в соответствии с выражениями $(1)-(5)(a)$; спектр НПВО образца А после термодиффузии бора при температуре $950^{\circ} \mathrm{C}$ (точки) и моделирование (линии) спектра с изменением параметра $\tau_{1}=11 \cdot 10^{-15}$ с в 2 раза $(b)$.

КНН $n_{\text {eff }}=\sqrt{\varepsilon_{\text {eff }}}$ рассчитывался исходя из модели анизотропной эффективной среды (обобщенной формулы Бруггемана) [9]:

$$
p \frac{1-\varepsilon_{\mathrm{eff}}}{\varepsilon_{\mathrm{eff}}+L\left(1-\varepsilon_{\mathrm{eff}}\right)}+(1-p) \frac{\varepsilon_{\mathrm{Si}}-\varepsilon_{\mathrm{eff}}}{\varepsilon_{\mathrm{eff}}+L\left(\varepsilon_{\mathrm{Si}}-\varepsilon_{\mathrm{eff}}\right)}=0,
$$

где $L-$ фактор деполяризации, величина которого равна $1 / 3$ в случае изотропного ансамбля нанокристаллов, а для системы бесконечных нитей $L=1 / 2$, если электрическое поле перпендикулярно оси цилиндрических нанонитей. С учетом случайного пространственного расположения кремниевых нанонитей и их нецилиндрической формы (см. рис. 1) нами в расчетах по формуле (3) использовалось значение $L=1 / 3$.
Диэлектрическая проницаемость кремниевой компоненты $\varepsilon_{\mathrm{Si}}$ рассматривалась с учетом друде-поглощения на свободных носителях заряда и рассеяния СН3 на поверхности нанонитей [10], а именно

$$
\varepsilon_{\mathrm{Si}}=\varepsilon_{\infty}-\frac{N_{p} q^{2}}{2 \pi c \nu m_{p} \varepsilon_{0}}\left[2 \pi c v+i \tau^{-1}\right]^{-1}
$$

где $N_{p}$ - концентрация свободных дырок, $m_{p}-$ их эффективная оптическая масса, $\varepsilon_{\infty}=11.7-$ высокочастотная диэлектрическая проницаемость кремния, $\tau$ - время рассеяния квазиимпульса носителей заряда, задаваемое выражением [10]

$$
\tau^{-1}=\tau_{0}^{-1}\left[1+\left(2 \pi c \nu \tau_{1}\right)^{-1}\right],
$$

где $\tau_{0}$ - время рассеяния квазиимпульса носителей заряда в объеме полупроводника, а величина $\tau_{1}$ учитывает столкновения носителей заряда с поверхностью КНН.

Концентрация свободных дырок в КНН была получена путем аппроксимации экспериментальных спектров НПВО по выражениям (1)-(5).

При известной пористости форма спектра НПВО массивов легированных КНН зависит от трех параметров: $N_{p}, \tau_{0}$ и $\tau_{1}$. Нулевое приближение $\tau_{0}$ в аппроксимации задавалось из зависимости величины времени жизни СНЗ в легированном бором объемном кремнии от их концентрации, полученной из ИК-спектров отражения. В результате аппроксимации спектров НПВО по указанным параметрам было достигнуто совпадение в пределах $1-3 \%$ (вне областей оксидных полос) модельных и экспериментальных спектров легированных образцов. Параметры аппроксимации приведены в табл. 2.

Дополнительно, для оценки глубины зондирования образцов в режиме НПВО, была определена спектральная зависимость глубины проникновения эванесцентной волны $d_{p}$ в массив КНН при наличии поглощения согласно [12]. Эффективный показатель преломления

Таблица 2. Значения концентраций СНЗ и времен рассеяния дырок для исследованных образцов, полученные из

\begin{tabular}{|c|c|c|c|c|}
\hline \multicolumn{5}{|c|}{ Образец А } \\
\hline $\begin{array}{c}\text { Температура } \\
\text { отжига, }{ }^{\circ} \mathrm{C}\end{array}$ & 850 & 900 & 950 & 1000 \\
\hline $\begin{array}{l}\tau_{0}, 10^{-15} \mathrm{c} \\
\tau_{1}, 10^{-15} \mathrm{c} \\
N_{p}, 10^{19} \mathrm{~cm}^{-3}\end{array}$ & $\begin{aligned} 13.5 & \pm 0.7 \\
14 & \pm 3 \\
0.43 & \pm 0.13\end{aligned}$ & $\begin{array}{l}9.0 \pm 0.5 \\
7.8 \pm 1.6 \\
2.9 \pm 0.6\end{array}$ & $\begin{array}{c}8.3 \pm 0.3 \\
11 \pm 3 \\
3.2 \pm 0.6\end{array}$ & $\begin{aligned} 11.0 & \pm 0.5 \\
9.5 & \pm 2 \\
1.3 & \pm 0.5\end{aligned}$ \\
\hline \multicolumn{5}{|c|}{ Образец В } \\
\hline $\begin{array}{c}\text { Температура } \\
\text { отжига, }{ }^{\circ} \mathrm{C}\end{array}$ & 850 & 900 & 950 & 1000 \\
\hline $\begin{array}{l}\tau_{0}, 10^{-15} \mathrm{c} \\
\tau_{1}, 10^{-15} \mathrm{c} \\
N_{p}, 10^{19} \mathrm{~cm}^{-3}\end{array}$ & $\begin{array}{r}12.0 \pm 0.7 \\
7.0 \pm 1.4 \\
0.5 \pm 0.2\end{array}$ & $\left|\begin{array}{c}8.3 \pm 0.3 \\
11 \pm 2 \\
2.9 \pm 0.6\end{array}\right|$ & $\begin{array}{c}8.8 \pm 0.5 \\
10 \pm 2 \\
2.7 \pm 0.6\end{array}$ & $\begin{array}{c}8.5 \pm 0.4 \\
14 \pm 3 \\
2.5 \pm 0.5\end{array}$ \\
\hline
\end{tabular}
аппроксимации экспериментальных данных НПВО по формулам $(1)-(5)$ 
массива КНН при расчетах также рассматривался в модели Бруггемана. Вычисления показали, что глубина проникновения практически не зависит от уровня легирования КНН вплоть до $N_{p}=5 \cdot 10^{19} \mathrm{~cm}^{-3}$. При пористости 70\% глубина проникновения эванесцентной волны составляет 1.5 мкм на низкочастотной границе исследуемого спектра НПВО и становится < $200 \mathrm{HM}$ при волновых числах, превышающих $3000 \mathrm{~cm}^{-1}$. Таким образом, $d_{p}$ одинакова для исходных и легированных при разных температурах образцов. Отметим, что реальная глубина зондирования в 2-3 раза превышает глубину проникновения эванесцентной волны, с которой извлекается основная информация [11].

\section{4. Заключение}

В работе показано, что для массивов КНН, сформированных методом металл-стимулированного химического травления кремния, дополнительное легирование бором позволяет достичь концентрации свободных дырок $\sim 10^{19} \mathrm{~cm}^{-3}$, диагностируемой методом ИКспектроскопии в режиме нарушенного полного внутреннего отражения. Анализ экспериментальных результатов в рамках модели эффективной среды позволяет также оценить времена рассеяния квазиимпульса свободных носителей заряда в кремниевых нанонитях. В целом использованные подходы к легированию кремниевых наноструктур и их оптической диагностике могут быть перспективны для развития методов получения сильно легированных наноматериалов для фотоники и термоэлектрических преобразователей.

\section{Благодарности}

Авторы благодарят Т. Ничипорук и Н.В. Латухину за предоставленные образцы легирующих растворов и полезные обсуждения. В работе использовалось оборудование Учебно-методического центра литографии и микроскопии МГУ им. М.В.Ломоносова.

\section{Финансирование работы}

Работа частично поддержана государственным заданием Министерства науки и высшего образования (проект 16.2969.2017/4.6).

\section{Конфликт интересов}

Авторы заявляют, что у них нет конфликта интересов.

\section{Список литературы}

[1] A.S. Kalyuzhnaya, A.I. Efimova, L.A. Golovan, K.A. Gonchar, V.Yu. Timoshenko. In: Silicon Nanomaterials Soursebook. Arrays, Functional Materials, and Industrial Nanosilicon, ed. by K.D. Sattler (CRC Press-Taylor \& Francis Group, 2017) p. 3.

[2] E. Krali, Z.A.K. Durrani. Appl. Phys. Lett., 102, 143102 (2013).
[3] H. Zhang, R. Zhang, K.S. Schramke, N.M. Bedford, K. Hunter, U.R. Kortshagen, P. Nordlander. ACS Photonics, 4 (4), 963 (2017).

[4] К.С. Секербаев, Е.Т. Таурбаев, А.И. Ефимова, В.Ю. Тимошенко, Т.И. Таурбаев. ФТП, 51 (8), 1095 (2017).

[5] H. Han, Z. Huang, W. Lee. Nano Today, 9, 271 (2014).

[6] S. Weidemann, M. Kockert, D. Wallacher, M. Ramsteiner, A. Mogilatenko, K. Rademann, S.F. Fischer. J. Nanomaterials, 2015, 672305 (2015).

[7] A.I. Hochbaum, R. Chen, R.D. Delgado, W. Liang, E.C. Garnett, M. Najarian, A. Majumdar, P. Yang. Nature Lett., 451, 163 (2008).

[8] S.P. Rodichkina, T. Nychyporuk, A. Pastushenko, V.Yu. Timoshenko. Phys. Status Solidi RRL, 12 (9), 1800224 (2018).

[9] Л.А. Головань, В.Ю. Тимошенко, П.К. Кашкаров. УФН, 177 (6), 619 (2007)

[10] Л.А. Осминкина, Е.В. Курепина, А.В. Павликов, В.Ю. Тимошенко, П.К. Кашкаров. ФТП, 38 (5), 603 (2004).

[11] F.M.Jr. Mirabella. Appl. Spectrosc. Rev., 21 (1-2), 45 (1985).

[12] M. Toriumi, M. Yanagimachi, H. Masuhara. Appl. Optics, 31 (30), 6376 (1992).

Редактор Г.А. Оганесян

\section{Determination of free charge carrier concentration in arrays of boron doped silicon nanowires using attenuated total reflection infrared spectroscopy}

\author{
E.A. Lipkova ${ }^{1}$, A.I. Efimova ${ }^{1}$, K.A. Gonchar ${ }^{1}$, \\ D.E. Presnov 2,1 , A.A. Eliseev ${ }^{3}$, A.N. Lapshin ${ }^{4}$, \\ V.Yu. Timoshenko $1,5,6$ \\ ${ }^{1}$ Lomonosov Moscow State University \\ (Faculty of Physics), \\ 119991 Moscow, Russia \\ 2 Lomonosov Moscow State University \\ (D.V. Skobeltsyn Institute of Nuclear Physics), \\ 119234 Moscow, Russia \\ ${ }^{3}$ Lomonosov Moscow State University \\ (Faculty of Materials Science), \\ 119991 Moscow, Russia \\ ${ }^{4}$ Bruker Ltd, \\ 119017 Moscow, Russia \\ ${ }^{5}$ National Research Nuclear University „MEPhl“, \\ PhysBio Institute, \\ 115409 Moscow, Russia \\ ${ }^{6}$ Lebedev Physical Institute, \\ Russian Academy of Sciences, \\ 119991 Moscow, Russia
}

Abstract Attenuated total reflection infrared spectroscopy was used to determine the free charge carrier concentration in the arrays of silicon nanowires of characteristic transverse dimension of $50-100 \mathrm{~nm}$ and the length of the order of $10 \mu \mathrm{m}$ which were formed on low-doped crystalline $p$-type silicon via metalstimulated chemical etching and subjected to additional thermodiffusion boron doping at the temperatures $850-1000^{\circ} \mathrm{C}$. It was found out that the free hole concentration varies from $5 \cdot 10^{18}$ to $3 \cdot 10^{19} \mathrm{~cm}^{-3}$ depending on the annealing temperature and reaches it's maximum at $900-950^{\circ} \mathrm{C}$. The results can be used to expand the scope of silicon nanowires application in photonics, sensorics and thermoelectric power converters. 